\title{
Ultrasonographic Evaluation of Placental Sites and Thickness at Second Trimester and Its Correlation with Pregnancy Outcome Ibrahim Mohiy El-Maghraby
}

Fellow, Obstetrics \& Gynecology Department, Shibin El Kom Teaching Hospital, Menoufia, Egypt

Corresponding author: Ibrahim El-Maghraby, Mobile: (+2)0100035 7896, E-mail: ibrahim_mohie@yahoo.com

\begin{abstract}
Background: Adverse fetal outcome has a wide spectrum of perinatal mortality and morbidity as low fetal Apgar score, admission to NICU, low birth weight, stillbirth \& maternal morbidity, and mortality. The use of ultrasonography of placental sites and thickness is the most effective method to estimate the adverse pregnancy outcome. Objective: To investigate the relationship between placental sites, diameter, and thickness at the second trimester with pregnancy outcome. Patients and Methods: the current study was conducted at the Obstetrics \& Gynecology Department in Shibin El Kom Teaching Hospital, on 200 pregnant women with a single fetus presenting for routine antenatal care in the second trimester, from September 2016 to August 2017. Detailed history, laboratory investigations, obstetric and ultrasound follow up study was done. Results: The mean age of all patients was $27.54 \pm 5.03$ years old. Placental sites were associated with placenta previa, placenta abruption, bleeding, FGR, and preterm delivery. Also, the placental diameter was highly related to placenta previa, placental abruption, bleeding and positively correlated with age and body mass index. Regarding, the placental thickness, it was highly associated with macrosomia and negatively correlated with age, and positively correlated with GA.

Conclusion: Placental implantation at the $18^{\text {th }}$ to $24^{\text {th }}$ weeks can be used as being at risk for adverse outcomes. Low placental implantation sites are associated with higher frequent preterm (labor \& deliveries) and lower postpartum hemorrhage. High lateral placental implantations are associated with lower Apgar scores.
\end{abstract}

Keywords: Placental site, Pregnancy outcome, Thickness, Second trimester, Ultrasonography.

\section{INTRODUCTION}

A detailed ultrasound for fetal anatomy is now routinely studied on most pregnant in the USA. Also, the evaluation of fetal anatomy, an assessment of the uterus placental implantation site, and its association with the internal cervical OS is noted (1). Ultrasonography is the preferred technique for placental localization. If a woman comes for the first time at term, even then a preliminary ultrasound examination for placental location is mandatory. One of the reasons for repeating the examination at the beginning of the third trimester is to determine the location of the placenta if it was described as a placenta previa at the midpregnancy examination ${ }^{(2)}$.

Pregnant women with placenta previa were found to had decreased risk of hypertensive disorders as compared with normally implanted placentas ${ }^{(2)}$. While, unilateral placental implantations have been associated with a higher incidence of preeclampsia, fetal distress in labor, abdominal deliveries, and intrauterine growth retardation ${ }^{(3)}$. The placenta is a fetal organ that provides the physiologic link between a pregnant woman and the fetus. The placenta develops from the chorionic villi at the implantation site at about the fifth week of gestation and by the ninth or tenth week, the diffuse granular echotexture of the placenta is apparent at sonography ${ }^{(4)}$. Recently, two-dimensional (2D) placental measurements have exhibited potential utility for predicting adverse outcomes in certain high-risk patients, possibly by serving as a marker of normal chorionic regression and placental growth ${ }^{(4)}$.

Second-trimester placental volumes measured by three-dimensional ultrasound have been used to identify fetuses at risk of growth restriction, while another study reported that ultrasonographic measurement of placental diameter and thickness is of prognostic value in identifying the subsequent occurrence of fetal growth restriction (5). This prediction of growth-restricted pregnancies from placental size is based on the fact that diminished placental size precedes fetal growth restriction ${ }^{(6)}$. The aim of this study was to determine the utility of two-dimensional (2D) sonographic placental location and measurements in the prediction of adverse pregnancy outcome.

\section{PATIENTS AND METHODS}

This observational cohort study was conducted at the Obstetrics \& Gynecology Department, Shibin El Kom Teaching Hospital, Menoufia, Egypt on 200 pregnant women with a single fetus presenting for routine antenatal care in the second trimester (between 18 and 24 weeks' gestation) from September 2016 to August 2017.

Ethical Considerations: All participants were volunteers. All of them signed written informed consent with explaining the aim of the study before the study initiation. Approval was obtained from the ethical committee at the Faculty of Medicine, Menoufia University.

Inclusion criteria: pregnant women with a single fetus presenting for routine antenatal care in the second trimester (between 18 and 24 weeks' gestation).

All the recruited women underwent ultrasonic placental localization and measurements and were followed via regular antenatal care visits in the outpatients' clinic to record obstetric outcomes. 
Placental localization: 10 distinct placental implantation sites were identified based on previous investigations assessing placental migration.

Placental measurements (diameter \& thickness) as follows:

(i) Scanning through the placenta from various angles to obtain the largest diameter possible; (ii) Measurement of the diameter along the fetal surface using a linear or bilinear approach (whichever is deemed a better fit); (iii) Measurement of the largest placental thickness in the same image; (iv) Rotating of the probe $90^{\circ}$ and scan to find the largest diameter in that plane; (v) repeat the same diameter and thickness measurement.

Outcomes considered: included the followings;

Placenta previa: Placenta previa is a low-lying placenta that covers part or all the Internal of the cervix.

Placental abruption: Placental abruption (sometimes called abruptio placentae) is a condition in which the placenta peels away from the uterine wall, partially or almost completely, before delivery.

Any bleeding during pregnancy, (APH - $\mathrm{PPH})$ :

In obstetrics, antepartum hemorrhage (APH), also hemorrhage, is genital bleeding during pregnancy from the 28th week (sometimes defined as from the 20th weeks' gestational age to term. Preterm labor (uterine contractions with cervical change), Preterm birth, also known as premature birth, is the birth of a baby at fewer than 37 weeks gestational age.

For all patients, the following procedures were performed:

- Careful history taking: e.g. high lighting age, parity, gestational age.

- Careful taking past history: for any medical disorder during previous pregnancies for multiparous women poor obstetric outcomes as FGR, IUFD, GDM, PE...etc.

- Family history: for hypertension, and diabetes mellitus.

\section{General examination: \\ Initial visit (18-24 weeks)}

A. Clinical examination: e.g. weight body mass index (BMI) was calculated (weight in kilograms divided by the square of height in meters), blood pressure, edema, and fetal heart sounds auscultation.

B. Laboratory investigation: including

- Detection of microalbuminuria by dipstick testing after asking the patient to bring a morning mid-stream sample on the day of examination. The presence of albumin is confirmed by 24 hours urine and a value of $300 \mathrm{mg} / 24$ hours urine is diagnostic of proteinuria.

- Fasting blood sugar normally from 70-110 mg/dl 2 hours post prandial up to $140 \mathrm{mg} / \mathrm{dl}$, using Sysmex KX21 automatized hematology analyzer (Sysmex Corporation, Japan). As well as Glycated $\mathrm{Hb}$ in indicated cases, $\leq 6.5$ was diagnostic of DM.

- Assessment of BPD, FL correlated to gestational age. Also, Measurement of placental thickness, diameters, sites \& Grading.

- $\quad$ Obstetric and Ultrasound follow up study (18-24 Wks): was done by a device (EM-2000, SHENZHEN electronic technology, co; LTD -tian Nanyou-Ind AreaShenzhen 518054).

\section{Statistical Analysis}

Results were analyzed and tabulated using Microsoft Excel version 7 (Microsoft Corporation, NY, USA) and SPSS v. 16. (SPSS Inc., Chicago, IL, USA). Two types of statistics were done: Descriptive: e.g. Percentage (\%), mean, median, and SD. Analytical: includes: Chi-Squared $\left(\chi^{2}\right)$, Wallis analysis of variance for comparing categorical data, and Person correlation coefficient ( $r$ ) for correlation between two dependents quantitative not normally distributed variable. A value of $\mathrm{P}<0.05$ was indicated statistically significant.

\section{RESULTS}

Table (1): Demographic and clinical data of the studied patients $(\mathrm{n}=200)$

\begin{tabular}{|l|c|c|}
\hline \multicolumn{2}{|c|}{ Clinical data } & \multicolumn{2}{c|}{ Studied patients $(\mathrm{n}=200)$} \\
\cline { 2 - 3 } & Mean \pm SD & Range \\
\hline Gestational age (GA) & $21.5 \pm 7.2$ & $16-33$ \\
\hline Age (years) & $27.54 \pm 5.03$ & $18-39$ \\
\hline $\begin{array}{l}\text { Body mass index } \\
\text { (kg/m2) }\end{array}$ & $28.95 \pm 8.12$ & $20-34$ \\
\hline Placental diameter & $12.16 \pm 1.42$ & $6-18$ \\
(cm) & & \\
\hline Placental thickness & $2.71+0.33$ & $1.5-6$ \\
(cm) & No & $\%$ \\
\hline Parity: & 20 & 10.0 \\
Primigravida & 180 & 90.0 \\
Multigravida & 17 & 8.5 \\
\hline Placental site: & 28 & 14.0 \\
high posterior & 8 & 4.0 \\
left high & 9 & 4.5 \\
right low & 7 & 3.5 \\
left low & 24 & 12.0 \\
central & 31 & 15.5 \\
high anterior & 25 & 12.5 \\
low anterior & 33 & 16.5 \\
fundal & 4 & 2.0 \\
right high & 4 & 2.0 \\
fundal anterior & 10 & 5.0 \\
fundal posterior & & \\
low posterior & & \\
\hline
\end{tabular}

SD: Stander deviation, FGR: Fetal Growth Restriction RH: Rhesus PPH: Postpartum hemorrhage DM HTN: Diabetes mellitus, hypertension APH: Antepartum hemorrhage

This table shows that the age of the patients ranged from 18-39 years with a mean of $27.54 \pm 5.03$ years old. Also, the mean BMI and gestational age of the patients were 28.95 \pm 8.12 (range; 20-34) and 21.5 \pm 7.2 (range; 16-33) respectively. Ten percent of patients had primigravida and $90 \%$ had multigravida. Prior uncomplicated pregnancy recorded the most frequency $(9.5 \%)$, Also, the mean of placental diameter and thickness were $12.16 \pm 1.42$ (range: $6-18$ ) and $2.71+0.33$ (range:1.5-6) respectively. Regarding placenta site, there was $16.5 \%$ right high; $15.5 \%$ low anterior; $14 \%$ left high and $12.5 \%$ fundal (Fig 1-6). 
Table (2): The relations between placental sites and adverse pregnancy outcomes

\begin{tabular}{|c|c|c|c|c|c|c|c|c|c|}
\hline \multirow{3}{*}{\multicolumn{2}{|c|}{ Pregnancy outcome }} & \multicolumn{6}{|c|}{ Placental Sites } & \multirow{3}{*}{$\chi^{2}$} & \multirow{3}{*}{ P-value } \\
\hline & & \multicolumn{2}{|c|}{ Fundal } & \multicolumn{2}{|c|}{ Lateral } & \multicolumn{2}{|c|}{ Low } & & \\
\hline & & No & $\%$ & No & $\%$ & No & $\%$ & & \\
\hline \multirow{2}{*}{ Placenta previa } & No 161 & 64 & 39.0 & 54 & 32.9 & 46 & 28.04 & \multirow{2}{*}{6.54} & \multirow{2}{*}{0.032} \\
\hline & Yes 36 & 10 & 27.8 & 8 & 22.2 & 18 & 50 & & \\
\hline \multirow{2}{*}{ Placental abruption } & Yes 14 & 11 & 60.0 & 2 & 26.7 & 2 & 13.3 & \multirow[b]{2}{*}{9.18} & \multirow{2}{*}{0.010} \\
\hline & No 183 & 63 & 34.1 & 60 & 32.4 & 62 & 33.5 & & \\
\hline \multirow[b]{2}{*}{ (APH-PPH) } & No 158 & 70 & 43.5 & 47 & 29.9 & 44 & 27.3 & \multirow{2}{*}{15.86} & \multirow{2}{*}{0.0003} \\
\hline & Yes 39 & 4 & 10.2 & 15 & 38.5 & 20 & 51.3 & & \\
\hline \multirow{2}{*}{ Preterm contraction } & No 192 & 73 & 37.4 & 59 & 30.3 & 63 & 32.3 & \multirow{2}{*}{2.023} & \multirow{2}{*}{0.364} \\
\hline & Yes 5 & 1 & 20 & 3 & 60.0 & 1 & 20.0 & & \\
\hline \multirow{2}{*}{ FGR } & No 176 & 72 & 40.2 & 58 & 32.4 & 49 & 27.4 & \multirow{2}{*}{17.2} & \multirow{2}{*}{0.001} \\
\hline & Yes 21 & 2 & 9.5 & 4 & 19.1 & 15 & 71.4 & & \\
\hline \multirow{2}{*}{ Abnormal presentation } & No 184 & 70 & 37.4 & 58 & 31.3 & 59 & 31.6 & \multirow{2}{*}{0.238} & \multirow{2}{*}{0.849} \\
\hline & Yes 13 & 4 & 30.8 & 4 & 30.8 & 5 & 38.5 & & \\
\hline \multirow{2}{*}{ Postpartum hemorrhage } & No 183 & 69 & 37.1 & 60 & 32.3 & 57 & 30.6 & \multirow{2}{*}{2.88} & \multirow{2}{*}{0.236} \\
\hline & \begin{tabular}{|l|} 
Yes 14 \\
\end{tabular} & 5 & 35.7 & 2 & 14.3 & 7 & 50.0 & & \\
\hline \multirow{2}{*}{ Macrosomia } & No 185 & 67 & 35.6 & 60 & 31.9 & 61 & 32.4 & \multirow{2}{*}{2.61} & \multirow{2}{*}{0.271} \\
\hline & Yes 12 & 7 & 58.3 & 2 & 16.7 & 3 & 25.0 & & \\
\hline \multirow{2}{*}{ Preeclampsia } & No 179 & 71 & 39.0 & 56 & 30.8 & 55 & 30.2 & \multirow{2}{*}{9.5} & 0000 \\
\hline & Yes 18 & 3 & 16.6 & 12 & 66.6 & 3 & 16.6 & & 0.008 \\
\hline & No 176 & 70 & 39.1 & 57 & 31.8 & 52 & 29.1 & 78 & \\
\hline  & Yes 21 & 4 & 19.1 & 5 & 23.8 & 12 & 57.1 & 1.01 & 0.029 \\
\hline
\end{tabular}

$\mathrm{X}^{2}$ : chi-square APH-PPH: Antepartum: Postpartum hemorrhage FGR: Fetal Growth Restriction

Table (2) shows that placental sites were associated with placenta previa $\left(\mathrm{x}^{2}=6.54, \mathrm{p}=0.032\right)$, placenta abruption $\left(x^{2}=9.18, p=0.010\right)$, bleeding $(A P H, P P H)\left(x^{2}=15.86, p=0.0003\right)$, FGR $\left(x^{2}=17.2, p=0.001\right)$, preeclampsia $\left(\mathrm{x}^{2}=9.5, \mathrm{p}=0.008\right)$ and preterm delivery $\left(\mathrm{x}^{2}=7.07, \mathrm{p}=0.029\right)$. While, no significant relation $(\mathrm{P}>0.05)$ was observed between placental sites and preterm contraction, abnormal presentation, postpartum hemorrhage and macrosomia.

Table (3): The relation between placental diameter and pregnancy outcome.

\begin{tabular}{|c|c|c|c|c|c|}
\hline \multirow{2}{*}{\multicolumn{2}{|c|}{ Pregnancy outcome }} & \multicolumn{2}{|c|}{ Placental diameter } & \multirow{4}{*}{$\begin{array}{c}\text { Mann-Whitney } \\
\text { Test }\end{array}$} & \multirow{4}{*}{$\frac{P \text {-value }}{0.0001}$} \\
\hline & & \multirow{2}{*}{$\begin{array}{c}\text { Mean } \pm \text { SD } \\
12.82 \pm 2.472\end{array}$} & \multirow{2}{*}{$\begin{array}{c}\text { Range } \\
7-20 \\
\end{array}$} & & \\
\hline \multirow{2}{*}{ Placenta previa } & No 161 & & & & \\
\hline & Yes 36 & $14.8 \pm 6.222$ & $9-20$ & & \\
\hline \multirow{2}{*}{ Placental abruption } & Yes 14 & $11.17 \pm 1.88$ & $7-14$ & \multirow{2}{*}{1.96} & \multirow{2}{*}{0.049} \\
\hline & No 183 & $12.91 \pm 2.438$ & $7-20$ & & \\
\hline \multirow{2}{*}{ Bleeding (APH-PPH) } & No 158 & $12.95 \pm 2.356$ & $7-20$ & \multirow{2}{*}{2.206} & \multirow{2}{*}{0.027} \\
\hline & Yes 39 & $12.28 \pm 2.645$ & $8-20$ & & \\
\hline \multirow{2}{*}{ Preterm labor } & No 192 & $12.81 \pm 2.435$ & $7-20$ & \multirow{2}{*}{0.173} & \multirow{2}{*}{0.863} \\
\hline & Yes 5 & $12.9 \pm 2.133$ & $10-15$ & & \\
\hline \multirow{2}{*}{ FGR } & No 176 & $12.79 \pm 2.492$ & $7-20$ & \multirow{2}{*}{0.552} & \multirow{2}{*}{0.581} \\
\hline & Yes 21 & $13.03 \pm 2.423$ & $7-20$ & & \\
\hline \multirow{2}{*}{ Abnormal presentation } & No 184 & $12.81 \pm 2.383$ & $7-20$ & \multirow[b]{2}{*}{0.127} & \multirow{2}{*}{0.899} \\
\hline & Yes 13 & $12.86 \pm 3.043$ & $8-18$ & & \\
\hline \multirow{2}{*}{ Post-partum hemorrhage } & No 183 & $12.79 \pm 2.42$ & $7-20$ & \multirow{2}{*}{0.859} & \multirow{2}{*}{0.39} \\
\hline & Yes 14 & $13.11 \pm 2.423$ & $7-17$ & & \\
\hline \multirow{2}{*}{ Preterm delivery } & No 176 & $12.86 \pm 2.484$ & $7-20$ & \multirow{2}{*}{0.979} & \multirow{2}{*}{0.327} \\
\hline & Yes 21 & $12.46 \pm 1.845$ & $10-17$ & & \\
\hline \multicolumn{4}{|c|}{ Age } & 0.242 & $0.001 *$ \\
\hline \multicolumn{4}{|c|}{ BMI } & 0.149 & $0.036^{*}$ \\
\hline \multicolumn{4}{|c|}{ Gestational age } & 0.035 & 0.630 \\
\hline
\end{tabular}

APH-PPH: Antepartum: Postpartum hemorrhage $\quad$ FGR: Fetal Growth Restriction $\quad$ BMI: body mass index

*: significant correlation at $\mathrm{p}<0.5$ level 
Table (3) shows that placental diameter was positively correlated with age $(r=0.242, p=0.001)$ and body mass index $(\mathrm{r}=0.149, \mathrm{p}=0.036)$, placenta previa $(\mathrm{p}=0.0001)$, placental abruption $(\mathrm{p}=0.049)$, and bleeding $(\mathrm{p}=0.027)$. But not correlated $(\mathrm{P}>0.05)$ with gestational, preterm labor, FGR, abnormal presentation, post-partum hemorrhage, and preterm delivery.

Table (4): The relation between pregnancy outcome and placental thickness.

\begin{tabular}{|c|c|c|c|c|c|}
\hline \multirow{2}{*}{\multicolumn{2}{|c|}{ Pregnancy outcome }} & \multicolumn{2}{|c|}{ Placental thickness } & \multirow{4}{*}{$\begin{array}{c}\text { Mann- } \\
\text { Whitney } \\
\text { Test }\end{array}$} & \multirow{4}{*}{\begin{tabular}{|c|} 
P-value \\
0.715
\end{tabular}} \\
\hline & & \multirow{3}{*}{$\begin{array}{l}\text { Mean } \pm \text { SD } \\
2.553 \pm 0.67 \\
2.481 \pm 0.55\end{array}$} & \multirow{3}{*}{$\begin{array}{l}\text { Range } \\
1.2-6.0 \\
1.8-5.0\end{array}$} & & \\
\hline Dloconte provi & $\mathrm{No}=163$ & & & & \\
\hline Flacenta previa & Yes $=36$ & & & & \\
\hline \multirow{2}{*}{ Placental abruption } & $\mathrm{No}=184$ & $2.54 \pm 0.67$ & $1.2-6.0$ & \multirow{2}{*}{0.181} & \multirow{2}{*}{0.856} \\
\hline & Yes $=15$ & $2.427 \pm 0.39$ & $1.5-3.0$ & & \\
\hline \multirow{2}{*}{ Bleeding } & $\mathrm{No}=160$ & $2.521 \pm 0.62$ & $1.2-6.0$ & \multirow{2}{*}{0.633} & \multirow{2}{*}{0.527} \\
\hline & Yes $=39$ & $2.62 \pm 0.75$ & $1.5-5.0$ & & \\
\hline \multirow{2}{*}{ Preterm labor } & $\mathrm{No}=194$ & $2.54 \pm 0.65$ & $1.2-6.0$ & \multirow{2}{*}{0.41} & \multirow{2}{*}{0.68} \\
\hline & Yes $=5$ & $2.50 \pm 0.46$ & $2.0-3.0$ & & \\
\hline \multirow{2}{*}{ FGR } & $\mathrm{No}=178$ & $2.54 \pm 0.68$ & $1.2-3.0$ & \multirow{2}{*}{9.5} & \multirow{2}{*}{$0.001 *$} \\
\hline & Yes $=21$ & $4.2 \pm 1.33$ & $1.5-6.0$ & & \\
\hline \multirow{2}{*}{ Abnormal presentation } & $\mathrm{No}=186$ & $2.52 \pm 0.64$ & $1.2-6.0$ & \multirow{2}{*}{0.95} & \multirow{2}{*}{0.34} \\
\hline & Yes $=13$ & $2.70 \pm 0.753$ & $2.0-4.4$ & & \\
\hline \multirow{2}{*}{ Preterm delivery } & $\mathrm{No}=178$ & $2.55 \pm 0.67$ & $1.2-6.0$ & \multirow{2}{*}{0.29} & \multirow{2}{*}{0.77} \\
\hline & Yes $=21$ & $2.40 \pm 0.37$ & $1.5-3.0$ & & \\
\hline \multirow{2}{*}{ Postpartum hemorrhage } & $\mathrm{No}=185$ & $2.53 \pm 0.66$ & $1.2-6.0$ & \multirow{2}{*}{1.05} & \multirow{2}{*}{0.29} \\
\hline & Yes $=14$ & $2.64 \pm 0.54$ & $1.8-4.0$ & & \\
\hline \multicolumn{4}{|c|}{ Age } & -0.180 & $0.011^{*}$ \\
\hline \multicolumn{4}{|c|}{ BMI } & 0.021 & 0.770 \\
\hline \multicolumn{4}{|c|}{ Gestational age } & 0.260 & $0.001 *$ \\
\hline
\end{tabular}

SD: stander deviation FGR: Fetal Growth Restriction BMI: body mass index

*: significant correlation at $\mathrm{p}<0.5$ level

Table (4) shows that placental thickness wasn't correlated ( $p>0.05$ ) with placenta previa, placental abruption, bleeding, preterm labor, abnormal presentation, preterm delivery, postpartum hemorrhage, and body mass index, while negatively correlated with age $(\mathrm{r}=-0.180, \mathrm{p}=0.011)$. Also, positively correlated with $\mathrm{FGR}\left(\mathrm{x}^{2}=9.5, \mathrm{p}=0.011\right)$, $\left(\mathrm{x}^{2}=9.4, \mathrm{p}=0.001\right)$ and gestational age $(\mathrm{r}=0.260, \mathrm{p}=0.001)$.

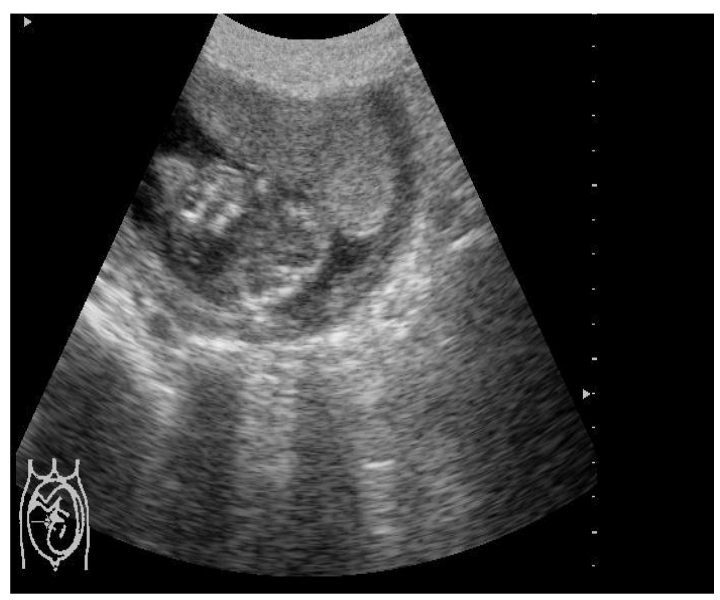

Fig 1: Primigravida +23 weeks, site left high thickness $3.66 \mathrm{~cm}$, diameter $7.4 \mathrm{~cm}$

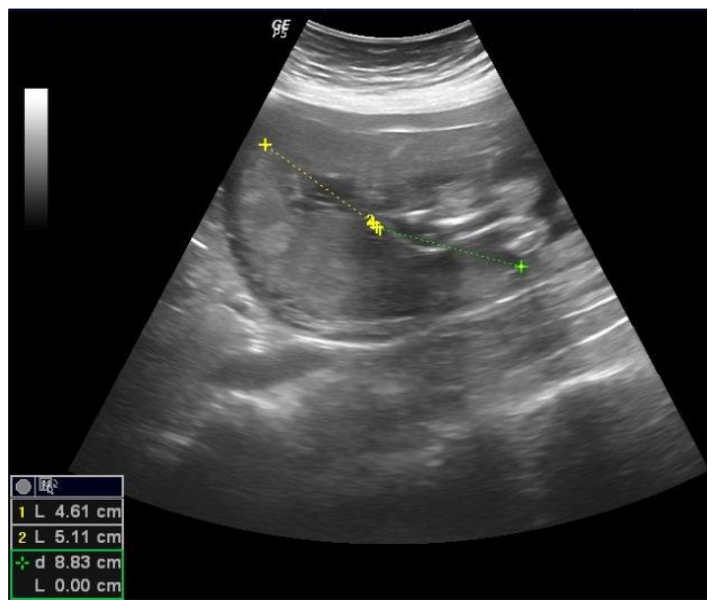

Fig 2: G3 P2 $+0+23$ weeks previous two sections, site right high, thickness $3.22 \mathrm{~cm}$, diameter $4.6 \mathrm{~cm} \times 5.11 \mathrm{~cm}$ 


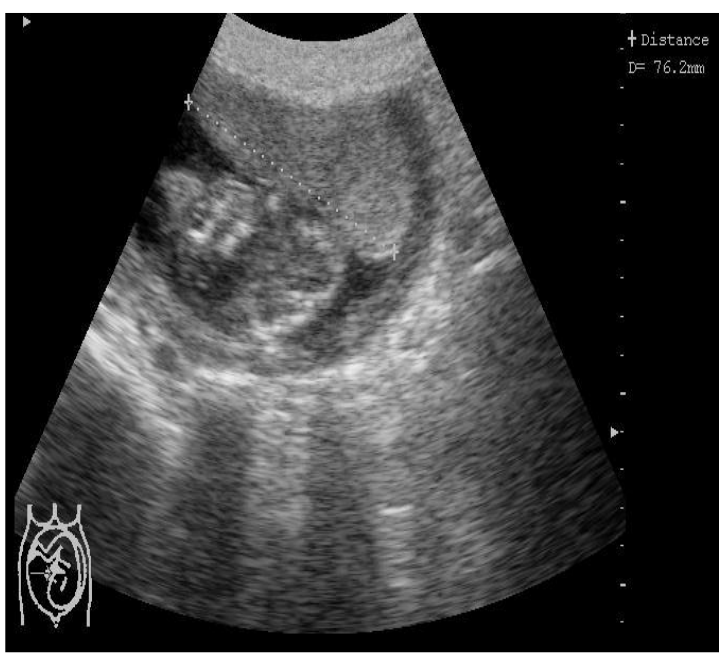

Fig 3: G2 P1 +0 + 18 weeks previous one section Site fundal anterior, thickness $3.59 \mathrm{~cm}$, diameter $7.62 \mathrm{~cm}$

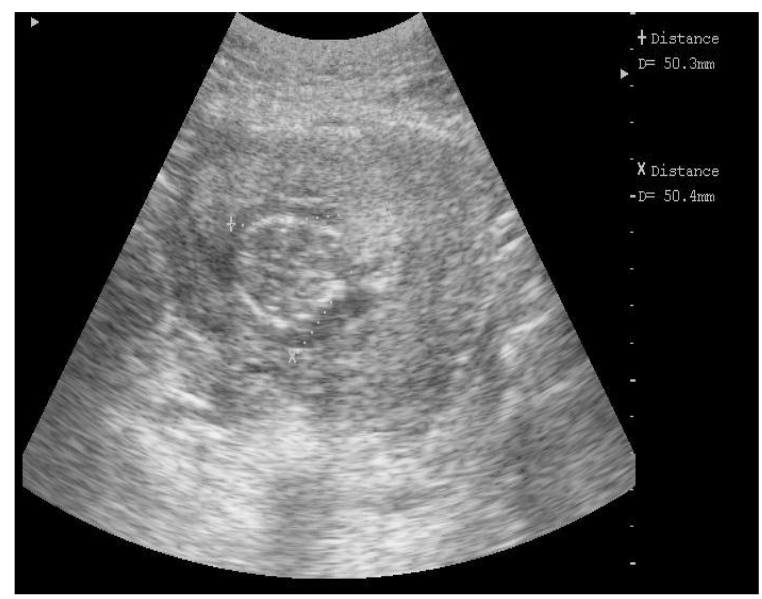

Fig 5: G4 P3 +0 + 23 weeks previous three sections, site anterior high, thickness $3.84 \mathrm{~cm}$, diameter $5.3 \mathrm{~cm} \times 5.4 \mathrm{~cm}$

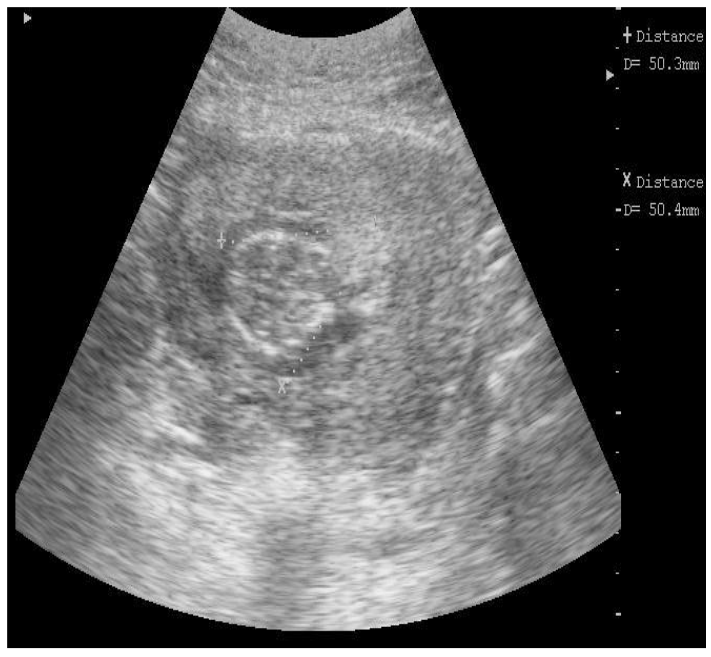

Fig 4: G4 P3 +0 + 23 weeks previous three sections, site anterior high thickness $3.84 \mathrm{~cm}$, diameter $5.3 \mathrm{~cm} \times 5.4 \mathrm{~cm}$

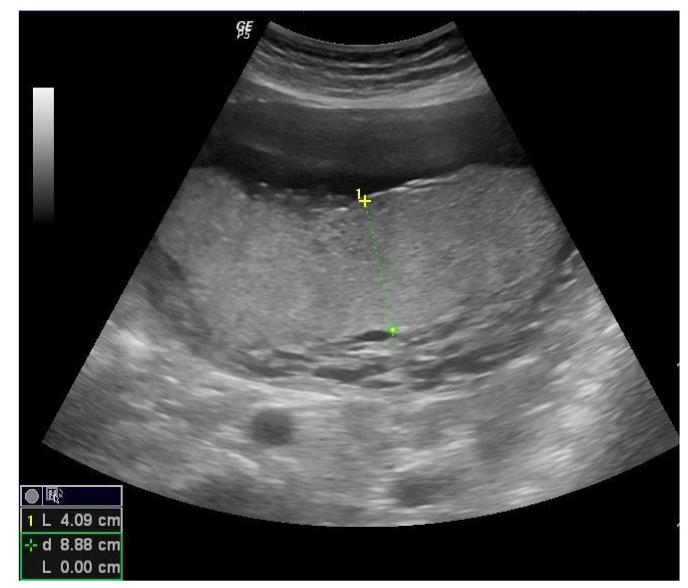

Fig 6: G3 P2 +0 + 24 weeks two normal vaginal delivery, site posterior low, thickness $4.09 \mathrm{~cm}$, diameter $13.35 \mathrm{~cm}$

\section{DISCUSSION}

Although multiple well-written texts are available on the pathology of the placenta, few sources specifically focus on the normal development and anatomy of this complex organ ${ }^{(7)}$. So, the purpose of this study was to determine the utility of twodimensional (2D) sonographic placental location and measurements in the prediction of adverse pregnancy outcome. This observational cohort study was conducted on 200 pregnant women with a single fetus presenting for routine antenatal care in the second trimester (between 18 and 24 weeks' gestation) to determine the utility of two-dimensional (2D) sonographic placental location and measurements in the prediction of adverse pregnancy outcome.

In this study mean age of patients was $27.54 \pm 5.03$ years old. While mean BMI and gestational ages were $28.95 \pm 8.12 \mathrm{~kg} / \mathrm{m}^{2}$ and $21.5 \pm 7.2$ years, respectively. Ten percent of patients had primigravida and $90 \%$ had multigravida. Also, the mean placental diameter and thickness were 12.81 \pm 2.423 and $2.54 \pm 0.6542$, respectively. Regarding placenta site, there was $16.5 \%$ right high; $15.5 \%$ low anterior; $14 \%$ left high and $12.5 \%$ fundal. Consistent with our findings, Adhikari et al. ${ }^{(8)}$ found that the age of patients ranged between 17 years to 35 years. The mean age was 22.64 years and an SD of 3.30. The minimum gestational age was 11.57 weeks and the maximum gestational age was 40.00 weeks with a mean gestational age of 25.49 weeks and an SD of 8.00. While mean of Placental thickness in $\mathrm{mm}$ was 21.83 \pm 0.19 . Additionally, thousand Saudi pregnant women were examined using ultrasound by Babiker and Eisa ${ }^{(9)}$, they found that patients ages were 16 to 45 years, the mean was 29 years old. Gestational ages (GA) of their fetuses were from (12th -40th) weeks. $21.9 \%$ of the participants were primigravida (PG). The mean GA was $38.1 \pm 0.89$ and the mean placental thickness was $39.6 \mathrm{~mm} \pm 7.0$. 
Moreover, Schwartz et al. (10) found that maximal placental thickness was significantly related to FGR where the mean of placental thickness was 2.9 \pm 0.6. Also, Ohagwu et al. (11) showed that the maximum mean placental thickness of $45.09 \pm 6.37$ $\mathrm{mm}$ was recorded at the 39 weeks of gestation, this is exceeded the current study results which suggested that the maximum mean placental thickness in the group (37th -40th) weeks was $39.6 \pm 7.0 \mathrm{~mm}$. While Sadler (12) showed that the maximum placental thickness of $45.10+6.37 \mathrm{~mm}$ was recorded at 39 weeks of gestation while the maximum estimated fetal weight was recorded at 41 weeks. It is possible that while the fetus continues to gain weight up to 41 weeks there is a fall in the placental increase in thickness at term.

Also, Stamnes Koepp et al. ${ }^{(13)}$ found that mean pre-pregnancy BMI was $24 \mathrm{~kg} / \mathrm{m}^{2}$ (SD 4.3), mean maternal weight change in the first 30 weeks of gestation was $9.3 \mathrm{~kg}$ (SD 4.4), mean birth weight was $3675 \mathrm{~g}$ (SD 487) and mean age 30.3 years. Afrakhteh et al. ${ }^{(14)}$ found that the mean age of cases was $26.4 \pm 5.1$. Values of mean birth and placental weights were $305.56 \pm 657.0$ and $551.7 \pm 104.8$ grams respectively. Mean \pm SD of gestational age was $268.2 \pm 22.3$ days. The percentage of macrosomia $(>4,000 \mathrm{~g})$ and low birth weight $(<2,500 \mathrm{~g})$ neonates at delivery were 2.5 and $14.6 \%$ respectively. Ultra-sonographic measures of placental thickness in the second and third trimester and changes between them were $21.68 \pm 4.52,36.26$ and $14.67 \pm 5.67 \mathrm{~mm}$ respectively, (14). It connects to the fetus by an umbilical cord of appr \pm 6.46 , proximately $55-60 \mathrm{~cm}(22-24 \mathrm{in}$.) in length at term with a diameter of 2.0 to $2.5 \mathrm{~cm}^{(15)}$.

The current study showed that placental sites were correlated with placenta previa, placenta abruption, bleeding (APH, PPH), FGR, and preterm delivery, and not correlated with preterm contraction, abnormal presentation, and postpartum hemorrhage. These results agree with several studies, Magann et al. (16) found that placental sites not correlated with pregnant ages $(\mathrm{p}=0.605)$ and macrosomia $(\mathrm{p}=0.271)$. Seadati et al. ${ }^{(17)}$ found that Low placental location was associated with increased risk of preterm labor and preterm delivery. Jang et al. ${ }^{(\mathbf{1 8})}$ indicated that placental sites weren't correlated with maternal age $(\mathrm{p}=0.073)$, and gestational age $(\mathrm{p}=0.058)$. Shumaila ${ }^{(19)}$ found that the anterior placenta was found to have a relation with placental abruption $(\mathrm{p}<0.001)$, while the posterior placenta had a significant association with preterm labor ( $\mathrm{p}<0.001)$. Triunfo et al. ${ }^{(20)}$ and Benton et al. ${ }^{(21)}$ suggested that an association between FGR and placental sites in these pregnancies as indicated by the presence of significant placental pathology. Sheiner $\boldsymbol{e t}$ $\boldsymbol{a l}{ }^{(22)}$ found an association between placenta previa and preterm delivery, cesarean sections, and placental abruption.
In contrast, our results disagree with Magann et al. ${ }^{(16)}$ who found that no relation between placental sites and placental abruption $(\mathrm{p}=0.10)$, bleeding $(\mathrm{p}=0.54)$. While that Rosenberg et al. ${ }^{(23)}$ did not find such an association between placenta previa and placental abruption. The discrepancies between these studies may have resulted from differences in maternal background, the gestational period at diagnosis, or patient management.

In the present investigation, age, body mass index, placenta previa, Placental abruption, and bleeding were positively correlated with placental diameter, but not correlated $(\mathrm{P}>0.05)$ with gestational age, preterm labor, FGR, abnormal presentation, postpartum hemorrhage, and preterm delivery. These findings correlate with the study of Das et al. ${ }^{\text {(24) }}$ who observed that the diameter of the placenta was less in hypertensive disorders and agreed with Damodaram $\boldsymbol{e t}$ al. ${ }^{(25)}$ found a reduced but positive correlation between the same association in growth-restricted fetuses. Similarly, a recent study by Sharma and Gupta ${ }^{(26)}$ found that approximate gestational age in weeks does not correspond to placental diameter. The subnormal placental diameter for age may be the earliest indicator of growth restriction. While, Gilbert-Barnass et al. ${ }^{(27)}$ found that clinically the abnormality presents with vaginal bleeding, in the second or third trimester or during labor, due to an associated placenta mebrenaca. Ultrasound has been used to detect this condition which found increased placental diameter.

In the current study, the placental thickness was positively correlated with FGR, gestational age, and negatively correlated with age, but not correlated with body mass index. Consistent with our findings, Ohagwu et al. ${ }^{(11)}$ conducted a study to determine the relationship between placental thickness and gestational age and found that there is a linear increase in mean placental thickness with gestational age. Similarly, a recent study by Mital et al. ${ }^{(28)}$ had reported that up to 21 weeks, the mean placental thickness was slighter higher than the gestational age $(1-4 \mathrm{~mm})$. Karthikeyan et al. (29) found a strong positive correlation between placental thickness and gestational age. Jain et al. ${ }^{(30)}$ found placental thickness $(\mathrm{mm})$ almost matched gestational age (weeks) from 27 weeks to 33 weeks of gestation. Similarly, in a recent study by Elchalal et al. (31) a linear increase of placental thickness was found to correlate with gestational age throughout pregnancy. Schwartz et al. (10) found that maximal placental thickness was significantly related to FGR (p-value 0.015) where the mean of placental thickness was $2.9 \pm 0.6$. Also, Raio et al. ${ }^{(32)}$ found that there was no significant correlation between placental thickness and abruption placenta $(\mathrm{p}=0.856)$.

\section{CONCLUSION}


Placental implantation at the $18^{\text {th }}$ to $24^{\text {th }}$ weeks can be used as being at risk for adverse outcomes. Low placental implantation sites are associated with higher frequent preterm (labor \& deliveries) and lower postpartum hemorrhage. High lateral placental implantations are associated with lower Apgar scores.

\section{REFERENCES}

1. Bhide A, Prefumo F, Moore J et al. (2003): Thilanganathan B Placental edge to internal os distance in the late third trimester and mode of delivery in placenta previa. BJOG., 110: 860-864.

2. Blouin-Demer G (2012): Precision and accuracy of body-size measurements in a constricting, large-bodied snake (Elaphe obsoleta) Herpetol. Rev., 34(4):320-323.

3. Bhalerao A, Kukarni S, Somalwar S (2013): Lateral placentation by ultrasonography: a simple predictor of preeclampsia. J South Asian Feder Obst Gynae., 5(2):6871.

4. Elsayed E, Tighiouart H, Griffith J (2007): Cardiovascular disease and subsequent kidney disease. Arch Intern Med., 167:1130-1136.

5. Habib F (2012): Prediction of low birth weight infants from ultrasound measurement of placental diameter and placental thickness. Ann Saudi Med., 22(5- 6):312-14.

6. Wolf H, Oosting H, Treffers P (2009): A longitudinal study of the relationship between placental fetal growth measured by ultrasonography. Am J Obstet Gynecol., 161:1140-5.

7. Pihar H (2006): The Preface. In: Human Placenta: Normal Developmental Biology. Core Curriculum Publishers. Pp. 4:1-2.

8. Adhikari R, Deka P, Tayal A et al. (2015): Ultrasonographic Evaluation of Placental Thickness in Normal Singleton Pregnancies for Estimation of Gestation Age. International J of Med Imag., 3(6): 143147

9. Babiker S, Eisa $\mathbf{R}$ (2014): Placenta Thickness Measurements during Gestational Age Progress. J of Appl Med Sci., 3(1):31-37

10. Schwartz M, Baskin D, Bukowski T et al. (2012): Specificity of leptin action on elevated blood glucose levels and hypothalamic neuropeptide $\mathrm{Y}$ gene expression in OB/OB mice. Diabetes, 45:531-535.

11. Ohagwu C, Abu P, Ezeokeke U et al. (2009): Relationship between placental thickness and growth parameters in normal Nigerian fetuses. Afr J Biotechnol., 8 (2): $133-8$.

12. Sadler T (2011): Longman's medical embryology. 9th edition. Baltimore, MD: Lippincott Williams and Wilkins., Pp. 117-48. https://bhumikapalrocks.files.wordpress.com/2016/02/la ngmans-medical-embryology-12th-ed.pdf

13. Stamnes Koepp U, Andersen L, Dahl-Joergensen $K$ (2012): Maternal pre-pregnant body mass index, maternal weight change, and offspring birthweight. Nordic Federation of Societies of Obstetrics and Gynecology, 91:243-249

14. Afrakhteh M, Moeini A, Taheri M et al. (203): Correlation between placental thickness in the second and third trimester and fetal weight. Rev Bras Ginecol Obstet., 35(7):317-22.

15. Baptiste-Roberts $K$, Salafia $C$, Nicholson $W$ et al. (2008): Maternal risk factors for abnormal placental growth: the national collaborative perinatal project. BMC Pregnancy Childbirth, 8:44-48.

16. Magann E, Doherty D, Turner K (2007): Secondtrimester placental location as a predictor of an adverse pregnancy outcome. J Perinatol., 27(1):9-14.

17. Seadati N, Najafian $M$, Cheraghi $M$ et al. (2013): Placental Location at Second Trimester and Pregnancy Outcomes. JPSI., 2(2): 32-34.

18. Jang D, We J, Shin J (2011): Maternal outcomes according to the placental position in placenta previa. Int J Med Sci., 8: 439-444.

19. Shumaila $Z$ (2013): Placental location and pregnancy outcome. J Turkish-German Gynecol Assoc., 14: 190193.

20. Triunfo S, Lobmaier S, Parra-Saavedra M (2014): Angiogenic factors at diagnosis of late-onset small-forgestational-age and histological placenta under perfusion, Placenta, 35 (6): 398-403.

21. Benton S, McCowan M, Placental H (2016): growth factor as a marker of fetal growth restriction caused by placental dysfunction. Placenta, 42:1-8.

22. Sheiner E, Shoham-Vardi I, Hallak M et al. (2001): Placenta previa: obstetric risk factors and pregnancy outcome. J Matern Fetal Med., 10: 414-419.

23. Rosenberg T, Pariente G, Sergienko R et al. (2011): Critical analysis of risk factors and outcome of placenta previa. Arch Gynecol Obstet., 284:47-51.

24. Das U, He J, Ehrhardt R et al. (2000): Time-dependent physiological regulation of ovine placental Glut-3 transporter protein. Am J Physiol., 279: 2252-2261.

25. Damodaram M, Story L, Eixrach E (2010): Placental MRI in intrauterine fetal growth restriction. Placenta, 31(6): 91-498.

26. Sharma K, Gupta M (2017): Caesarean Section: A technical update. AOGD BULLETIN, 17(4):9-12.

27. Gilbert-Barnass E, Ahmed A (2003): Placenta membranacea: A developmental anomaly with diverse clinical presentation. Pediatr Dev Pathol., 6:201-202.

28. Mital P, Hooja N, Mehndiratta K (2002): Placental thickness: a sonographic parameter for estimating the gestational age of the fetus. Indian J Radiol Imaging, 12 (4): 553-554.

29. Karthikeyan T, Subramaniam R, Johnson W et al. (2012): Placental thickness \& its correlation to gestational age \& fetal growth parameters a crosssectional ultrasonographic study. J Clin Diagn Res., 6(10):1732-1735.

30. Jain A, Kumar G, Agarwal U (2001): Placental thickness: a sonographic indicator of gestational age. J Obstet Gynaecol India, 51 (3): 48-49.

31. Elchalal U, Ezra Y, Levi Y (2000): Sonographically thick placenta: a marker for increased perinatal risk a prospective cross-sectional study. Placenta, 21:268-272.

32. Raio L, Ghezzi F, Cromi A et al. (2004): The thick heterogeneous (jellylike) placenta: a strong predictor of adverse pregnancy outcome. Prenat Diagn., 24: 182-188. 